\title{
Fatal Diaphragmatic Hernia following Radiofrequency Ablation for Hepatocellular Carcinoma: A Case Report and Literature Review
}

\author{
Tomoko Saito $^{a}$ Tetsuhiro Chiba $^{a}$ Sadahisa Ogasawara ${ }^{a}$ \\ Masanori Inoue $^{a}$ Toru Wakamatsu $^{a}$ Tenyu Motoyama ${ }^{a}$ \\ Naoya Kanogawa ${ }^{a}$ Eiichiro Suzuki ${ }^{a}$ Yoshihiko Ooka ${ }^{a}$ Akinobu Tawada ${ }^{a}$ \\ Hisahiro Matsubarab Osamu Yokosuka ${ }^{a}$ \\ Departments of a Gastroenterology and Nephrology, and ${ }^{b}$ Frontier Surgery, Graduate \\ School of Medicine, Chiba University, Chiba, Japan
}

\section{Key Words}

Hepatocellular carcinoma · Radiofrequency ablation · Diaphragmatic hernia · Liver cirrhosis

\begin{abstract}
An 81-year-old man was admitted to our hospital because of right quadrant abdominal pain. On admission, his liver function was Child-Pugh grade C (10 points). Computed tomography (CT) revealed a diaphragmatic herniation of bowel loops into the right thoracic cavity, accompanied by pleural effusion. Although diaphragmatic hernia was successfully repaired by emergency surgery, he died of liver failure 23 days after the surgery. A retrospective reading of CT images revealed the presence of diaphragmatic injury after radiofrequency ablation (RFA) which had been conducted 33 months before the development of diaphragmatic hernia. Of importance, the lesion of the diaphragmatic injury was located on the estimated needle track of RFA for hepatocellular carcinomas in segment 5 and segment 5/8, but not adjacent to their ablation areas. Subsequently, diaphragmatic perforation had been observed 24 months before admission. This suggests that diaphragmatic hernia caused by RFA is not necessarily due to thermal damage of ablation and is possibly life-threatening, at least in some patients with an impaired liver function.




\section{Case Reports in Oncology}

\begin{tabular}{l|l}
\hline \multicolumn{2}{l}{ Case Rep Oncol 2015;8:238-245 } \\
\hline DOI: 10.1159/000431310 & $\begin{array}{l}\text { ○ 2015 S. Karger AG, Basel } \\
\text { www.karger.com/cro }\end{array}$ \\
\hline
\end{tabular}

Saito et al.: Fatal Diaphragmatic Hernia following Radiofrequency Ablation for Hepatocellular Carcinoma: A Case Report and Literature Review

\section{Introduction}

Hepatocellular carcinoma (HCC) is the sixth most common malignancy in the world and the third most common cause of cancer-related death [1]. Recent progress in new therapeutic approaches has contributed to improvements in the survival and prognosis of patients with HCC. Radiofrequency ablation (RFA) has been widely applied for the local treatment of HCC [2]. The overall survival of patients treated with RFA was shown to be comparable to that of patients receiving hepatic resection [3]. Although RFA appears to be minimally invasive and comparatively safe, it sometimes causes severe complications due to thermal damage to organs adjacent to the liver [4].

Diaphragmatic hernias are defined as congenital or acquired defects in the diaphragm and present as a protrusion of an abdominal structure into the thoracic cavity. Acquired diaphragmatic hernias are generally caused by blunt or penetrating thoraco-abdominal trauma or iatrogenic injury [5]. This is associated with symptoms of ileus, dyspnea, chest pain, pleural effusion, and right shoulder pain. However, little is known about the clinical condition and the therapeutic approach of diaphragmatic hernia caused by RFA.

The current case report presents a case complicated by diaphragmatic hernia caused by RFA. Although the diaphragmatic hernia was immediately repaired surgically, the patient died of liver failure. We also reviewed reports of a total of 10 patients exhibiting diaphragmatic hernia after RFA and compared the clinical conditions of these and the present patient.

\section{Case Report}

An 81-year-old man was admitted to our hospital because of right upper quadrant abdominal pain. He had been followed for hepatitis $\mathrm{C}$ virus-related liver cirrhosis and recurrent HCC. He had received RFA treatment for HCC located in segment 5 as an initial treatment for HCC 50 months before admission. Thirty-three months before admission, he had undergone RFA for recurrent HCCs located in segment 5 , segment 8 , and segment $5 / 8$. Thereafter, he again received RFA for recurrent HCC in segment 3 at 28 months before admission. Because he had exhibited a large amount of right pleural effusion 3 months earlier, he had received best supportive care, including repeated thoracentesis and albumin administration.

On admission, the patient was afebrile and showed a normal consciousness level. Blood gas analysis showed modest hypoxemia caused by impaired pulmonary oxygenation $\left(\mathrm{PaO}_{2}\right.$ : $59 \mathrm{~mm} \mathrm{Hg}, \mathrm{SaO}_{2}$ : 93.1\%; table 1). Serum levels of liver transaminase, including aspartate transaminase and alanine transaminase, were within their normal ranges. However, serum levels of alkaline phosphatase and total bilirubin were abnormally high (468 IU/l and 3.0 $\mathrm{mg} / \mathrm{dl}$, respectively). Renal function markers, such as blood urea nitrogen and creatinine, were normal. The serum level of ammonia was $37 \mu \mathrm{g} / \mathrm{dl}$. Blood count tests showed pancytopenia. The white blood cell count, hemoglobin concentration, and number of platelets were $2,000 / \mu \mathrm{l}, 9.8 \mathrm{~g} / \mathrm{dl}$, and $6.9 \times 10^{4} / \mu \mathrm{l}$, respectively. Both the prothrombin time and activated partial thromboplastin time were prolonged (12.8 and $47.2 \mathrm{~s}$, respectively). Although antihepatitis $C$ virus antibody was positive, hepatitis B surface antigen was negative. The levels of $\alpha$-fetoprotein and protein induced by vitamin K absence or antagonist-II increased to 12.4 $\mathrm{ng} / \mathrm{ml}$ and $171 \mathrm{mAU} / \mathrm{ml}$, respectively. The Child-Pugh score of the patient was 10 (class C).

Computed tomography (CT) on admission revealed a right diaphragmatic hernia containing loops of the bowel and pleural effusion (fig. 1). Of importance, retrospective reading of CT images after the second RFA, conducted 33 months before admission, showed an inadequately enhanced lesion at the diaphragm along the needle track to the segment 5 and seg- 
Saito et al.: Fatal Diaphragmatic Hernia following Radiofrequency Ablation for Hepatocellular Carcinoma: A Case Report and Literature Review

ment 5/8 tumors (fig. 2a, b). Furthermore, the lesion showed diaphragm perforation 24 months before the onset of diaphragmatic hernia (fig. 2c). The diaphragm perforation was also observed 4 months before admission (fig. 2 d).

The patient underwent emergent surgery to repair the diaphragmatic herniation. The hernia hole was $4 \mathrm{~cm}$ in diameter and successfully closed. Because intestinal necrosis was not observed, bowel resection was not required. There were no severe postoperative complications, such as infection or ileus. Although the postoperative course was uneventful, his hepatic function gradually became exacerbated. Eventually, he died of liver failure 23 days after the operation.

\section{Discussion}

According to the algorithm for treatment specified in the Japan Society of Hepatology HCC guidelines, RFA is an appropriate therapeutic approach for patients with early-stage HCC who are not suitable for surgical resection [6]. Although RFA shows satisfactory local tumor control and minimal invasiveness, it often causes complications, including death, hemorrhage, needle-track seeding, intrahepatic abscess, perforation of gastrointestinal viscus, liver failure, biloma, biliary stricture, portal vein thrombosis, hemothorax, and pneumothorax [4, 7-10]. Recently, iatrogenic diaphragmatic hernia accompanied by RFA, a rare but important complication, has been reported [11-20]. Therefore, we reviewed a total of 10 case reports (articles written in English obtained from PubMed) documenting diaphragmatic hernia following RFA for HCC and compared the clinical conditions of these and the present patient (table 2).

The tumor location is closely related to the risk of injury to organs adjacent to the liver due to the thermal damage caused by RFA. All 10 previous patients had a history of RFA treatment for HCCs with right dome lesions of segment 7 or segment 8 and showed rightsided diaphragmatic hernia. Although no information was available for 1 patient, the remaining 9 patients had an RFA-treated lesion adjacent to the diaphragm. To avoid injury of the diaphragm, RFA targeting tumors near the diaphragmatic surface upon the liver might be performed with the introduction of subphrenic artificial ascites and carbon dioxide to separate the tumor from the diaphragm [21,22]. In the present patient, it was speculated that diaphragmatic injury had been caused by RFA performed 33 months before admission. Notably, the diaphragmatic area of injury appeared to be on the needle track to the tumors located in segment 5 or segment $5 / 8$, but it was not in direct contact with the diaphragm. Head et al. [23] demonstrated that diaphragmatic thickening was the most common imaging finding observed in patients receiving RFA for HCC adjacent to the diaphragm. However, postablation CT images in our patient revealed diaphragmatic thinning along the needle track. Taken together, it is possible that the diaphragmatic injury was caused by a factor other than thermal damage.

In addition, the interval between RFA therapy and diaphragmatic herniation ranged from 7 to 96 months (mean: 24 months). This indicates that diaphragmatic hernia is a lateonset complication of RFA for HCC. Consistent with this, the present patient showed diaphragmatic damage and diaphragmatic perforation 33 and 24 months before the development of diaphragmatic hernia, respectively. Taken together, it is possible that additional factors are necessary to develop diaphragmatic hernia. It has been reported that a poor liver function, hepatic cirrhosis, the use of an expandable type of RFA needle, pleural effusion, and other complications with an elevated abdominal pressure, including ascites and ileus, are related to the risk of diaphragmatic hernia [18]. The 10 previous diaphragmatic hernia pa- 
Saito et al.: Fatal Diaphragmatic Hernia following Radiofrequency Ablation for Hepatocellular Carcinoma: A Case Report and Literature Review

tients reported were complicated by cirrhosis. Concordant with this finding, the liver function of our patient was Child-Pugh grade C (10 points). Additionally, both pleural effusion and ascites were observed after the second RFA. Chilaiditi syndrome is characterized by the interpositioning of the intestine between the atrophic liver and diaphragm [24]. Although this is also responsible for diaphragmatic hernia, the present patient exhibited no Chilaiditi sign until the occurrence of diaphragmatic hernia.

Among the 10 previous patients, 8 received surgery and the remaining 2 patients underwent conservative treatment, including diuretic administration and albumin preparations to decrease the pleural effusion. Although 1 patient died of ruptured HCC, the remaining 9 patients survived after the operation for diaphragmatic hernia. The present patient underwent emergent surgical repair after providing informed consent but, unexpectedly, died only 23 days after the operation. It has been reported that decompensated cirrhosis is closely associated with perioperative complications and mortality when performing surgical procedures under anesthesia [25]. Further analyses are necessary to determine the indication of surgery for diaphragmatic hernia in patients with decompensated cirrhosis.

In conclusion, we report a fatal case of diaphragmatic hernia caused by RFA. Our case suggests that diaphragmatic hernia could be a delayed adverse event after RFA and a complication, at least in some patients with decompensated cirrhosis. Additionally, it is suggested that diaphragmatic injury is possible even if the ablated tumor is not adjacent to the diaphragm. If the diaphragmatic defect is recognized after RFA, prophylactic surgical repair might be considered.

\section{Statement of Ethics}

This study complied with the guidelines for human studies. Informed consent was not obtained because of the retrospective design (case report). The patient records/information were anonymized to protect the confidentiality of the personal information.

\section{Disclosure Statement}

The authors have no conflicts of interest.

\section{References}

1 Ferlay J, Shin HR, Bray F, et al: Estimates of worldwide burden of cancer in 2008: Globocan 2008. Int J Cancer 2010;127:2893-2917.

2 Gazelle GS, Goldberg SN, Solbiati L, et al: Tumor ablation with radio-frequency energy. Radiology 2000;217:633-646.

3 Cho YK, Kim JK, Kim MY, et al: Systematic review of randomized trials for hepatocellular carcinoma treated with percutaneous ablation therapies. Hepatology 2009;49:453-459.

4 Livraghi T, Solbiati L, Meloni MF, et al: Treatment of focal liver tumors with percutaneous radio-frequency ablation: complications encountered in a multicenter study. Radiology 2003;226:441-451.

5 Crandall M, Popowich D, Shapiro M, et al: Posttraumatic hernias: historical overview and review of the literature. Am Surg 2007;73:845-850.

-6 Kokudo N, Hasegawa K, Akahane M, et al: Evidence-based clinical practice guidelines for hepatocellular carcinoma: the Japan Society of Hepatology 2013 update (3rd JSH-HCC guidelines). Hepatol Res 2015;45:123-127.

7 Curley SA, Marra P, Beaty K, et al: Early and late complications after radiofrequency ablation of malignant liver tumors in 608 patients. Ann Surg 2004;239:450-458. 


\section{Case Reports in Oncology}

\begin{tabular}{l|l}
\hline \multicolumn{2}{l|}{ Case Rep Oncol 2015;8:238-245 } \\
\hline DOI: $10.1159 / 000431310$ & $\begin{array}{l}\text { C } 2015 \text { S. Karger AG, Basel } \\
\text { www.karger.com/cro }\end{array}$ \\
\hline
\end{tabular}

Saito et al.: Fatal Diaphragmatic Hernia following Radiofrequency Ablation for Hepatocellular Carcinoma: A Case Report and Literature Review

8 Kong WT, Zhang WW, Qiu YD, et al: Major complications after radiofrequency ablation for liver tumors: analysis of 255 patients. World J Gastroenterol 2009;15:2651-2656.

-9 Minami Y, Kudo M: Radiofrequency ablation of hepatocellular carcinoma: a literature review. Int J Hepatol 2011;2011:104685.

10 Bertot LC, Sato M, Tateishi R, et al: Mortality and complication rates of percutaneous ablative techniques for the treatment of liver tumors: a systematic review. Eur Radiol 2011;21:2584-2596.

11 Koda M, Ueki M, Maeda N, et al: Diaphragmatic perforation and hernia after hepatic radiofrequency ablation. AJR Am J Roentgenol 2003;180:1561-1562.

$\checkmark 12$ Shibuya A, Nakazawa T, Saigenji K, et al: Diaphragmatic hernia after radiofrequency ablation therapy for hepatocellular carcinoma. AJR Am J Roentgenol 2006;186:S241-S243.

13 di Francesco F, di Sandro S, Doria C, et al: Diaphragmatic hernia occurring 15 months after percutaneous radiofrequency ablation of a hepatocellular cancer. Am Surg 2008;74:129-132.

14 Boissier F, Labbé V, Marchetti G, et al: Acute respiratory distress and shock secondary to complicated diaphragmatic hernia. Intensive Care Med 2011;37:725-726.

15 Singh M, Singh G, Pandey A, et al: Laparoscopic repair of iatrogenic diaphragmatic hernia following radiofrequency ablation for hepatocellular carcinoma. Hepatol Res 2011;41:1132-1136.

16 Yamagami T, Yoshimatsu R, Matsushima S, et al: Diaphragmatic hernia after radiofrequency ablation for hepatocellular carcinoma. Cardiovasc Intervent Radiol 2011;34:S175-S177.

17 Kim JS, Kim HS, Myung DS, et al: A case of diaphragmatic hernia induced by radiofrequency ablation for hepatocellular carcinoma. Korean J Gastroenterol 2013;62:174-178.

18 Zhou M, He H, Cai H, et al: Diaphragmatic perforation with colonic herniation due to hepatic radiofrequency ablation: a case report and review of the literature. Oncol Lett 2013;6:1719-1722.

19 Nomura R, Tokumura H, Furihata M: Laparoscopic repair of a diaphragmatic hernia associated with radiofrequency ablation for hepatocellular carcinoma: lessons from a case and the review of the literature. Int Surg 2014;99:384-390.

20 Nakamura T, Masuda K, Thethi RS, et al: Successful surgical rescue of delayed onset diaphragmatic hernia following radiofrequency ablation for hepatocellular carcinoma. Ulus Travma Acil Cerrahi Derg 2014;20:295-299.

21 Raman SS, Aziz D, Chang X, et al: Minimizing diaphragmatic injury during radiofrequency ablation: efficacy of intraabdominal carbon dioxide insufflation. AJR Am J Roentgenol 2004;183:197-200.

22 Rhim H, Lim HK, Kim YS, et al: Percutaneous radiofrequency ablation with artificial ascites for hepatocellular carcinoma in the hepatic dome: initial experience. AJR Am J Roentgenol 2008;190:91-98.

23 Head HW, Dodd GD 3rd, Dalrymple NC, et al: Percutaneous radiofrequency ablation of hepatic tumors against the diaphragm: frequency of diaphragmatic injury. Radiology 2007;243:877-884.

24 Kamiyoshihara M, Ibe T, Takeyoshi I: Chilaiditi's sign mimicking a traumatic diaphragmatic hernia. Ann Thorac Surg 2009;87:959-961.

25 Ziser A, Plevak DJ, Wiesner RH, et al: Morbidity and mortality in cirrhotic patients undergoing anesthesia and surgery. Anesthesiology 1999;90:42-53. 


\section{Case Reports in Oncology}

\begin{tabular}{l|l}
\hline \multicolumn{2}{l|}{ Case Rep Oncol 2015;8:238-245 } \\
\hline DOI: $10.1159 / 000431310$ & $\begin{array}{l}\text { C 2015 S. Karger AG, Basel } \\
\text { www.karger.com/cro }\end{array}$ \\
\hline
\end{tabular}

Saito et al.: Fatal Diaphragmatic Hernia following Radiofrequency Ablation for Hepatocellular Carcinoma: A Case Report and Literature Review

Table 1. Laboratory data on admission

\begin{tabular}{|c|c|}
\hline \multicolumn{2}{|l|}{ Blood cell count } \\
\hline $\mathrm{WBC}, / \mu \mathrm{l}$ & 2,000 \\
\hline $\mathrm{RBC}, \times 10^{4} / \mu \mathrm{l}$ & 2.77 \\
\hline $\mathrm{Hb}, \mathrm{g} / \mathrm{dl}$ & 9.8 \\
\hline $\mathrm{Ht}, \%$ & 28.3 \\
\hline Plt, $\times 10^{4} / \mu \mathrm{l}$ & 6.9 \\
\hline \multicolumn{2}{|l|}{ Coagulation } \\
\hline PT, s & 12.8 \\
\hline PT-INR & 1.06 \\
\hline APTT, s & 47.2 \\
\hline \multicolumn{2}{|l|}{ Tumor markers } \\
\hline AFP, ng/ml & 12.4 \\
\hline AFP-L3, \% & 30.9 \\
\hline PIVKA-II, mAU/ml & 171 \\
\hline \multicolumn{2}{|l|}{ Blood chemistry } \\
\hline $\mathrm{TP}, \mathrm{g} / \mathrm{dl}$ & 7.5 \\
\hline $\mathrm{Alb}, \mathrm{g} / \mathrm{dl}$ & 3.2 \\
\hline $\mathrm{T}-\mathrm{Bil}, \mathrm{mg} / \mathrm{dl}$ & 3.0 \\
\hline AST, IU/l & 53 \\
\hline ALT, IU/l & 23 \\
\hline LDH, IU/l & 164 \\
\hline ALP, IU/l & 468 \\
\hline$\gamma$-GTP, IU/l & 23 \\
\hline T-Cho, mg/dl & 146 \\
\hline BUN, mg/dl & 18 \\
\hline Cre, mg/dl & 0.99 \\
\hline $\mathrm{NH}_{3}, \mu \mathrm{g} / \mathrm{dl}$ & 37 \\
\hline \multicolumn{2}{|l|}{ Serology } \\
\hline $\mathrm{CRP}, \mathrm{mg} / \mathrm{dl}$ & 0.2 \\
\hline HBsAg & $(-)$ \\
\hline HCV-Ab & $(+)$ \\
\hline HIV-Ab & $(-)$ \\
\hline \multicolumn{2}{|l|}{ Blood gas analysis } \\
\hline $\mathrm{pH}$ & 7.44 \\
\hline $\mathrm{PaCO}_{2}, \mathrm{~mm} \mathrm{Hg}$ & 32 \\
\hline $\mathrm{PaO}_{2}, \mathrm{~mm} \mathrm{Hg}$ & 59 \\
\hline $\mathrm{HCO}_{3}, \mathrm{mEq} / \mathrm{l}$ & 21.7 \\
\hline $\mathrm{BE}, \mathrm{mmol} / \mathrm{l}$ & -2.5 \\
\hline $\mathrm{SaO}_{2}, \%$ & 93.1 \\
\hline
\end{tabular}

$\mathrm{WBC}=$ White blood cell count; $\mathrm{RBC}=$ red blood cell count; $\mathrm{Hb}=$ hemoglobin; $\mathrm{Ht}=$ hematocrit; $\mathrm{Plt}=$ platelets; $\mathrm{PT}=$ prothrombin time; $\mathrm{PT}-\mathrm{INR}=$ prothrombin time-international normalized ratio; APTT $=$ activated partial thromboplastin time; AFP = $\alpha$-fetoprotein; AFP-L3 $=\alpha$-fetoprotein L3; PIVKA-II = protein induced by vitamin $\mathrm{K}$ absence or antagonist-II; TP = total protein; $\mathrm{Alb}=$ albumin; T-Bil = total bilirubin; AST = aspartate transaminase; ALT = alanine transaminase; $\mathrm{LDH}=$ lactate dehydrogenase; ALP = alkaline phosphatase; $\gamma$ GTP = gamma glutamyl transferase; T-Cho = total cholesterol; $\mathrm{BUN}=$ blood urea nitrogen; $\mathrm{Cre}=$ creatinine; $\mathrm{NH}_{3}=$ ammonia; $\mathrm{CRP}=\mathrm{C}$-reactive protein; $\mathrm{HBsAg}=$ hepatitis B surface antigen; HCV-Ab = anti-hepatitis C virus antibody; $\mathrm{HIV}-\mathrm{Ab}=\mathrm{HIV}$ antibody; $\mathrm{BE}=$ base excess. 


\section{Case Reports in Oncology}

\begin{tabular}{l|l}
\hline Case Rep Oncol 2015;8:238-245 \\
\hline DOI: $10.1159 / 000431310$ & $\begin{array}{l}\text { C 2015 S. Karger AG, Basel } \\
\text { www.karger.com/cro }\end{array}$ \\
\hline
\end{tabular}

Saito et al.: Fatal Diaphragmatic Hernia following Radiofrequency Ablation for Hepatocellular Carcinoma: A Case Report and Literature Review

Table 2. Characteristics of 11 diaphragmatic hernia patients following RFA for HCC

\begin{tabular}{|c|c|c|c|c|c|c|}
\hline $\begin{array}{l}\text { Age, } \\
\text { years }\end{array}$ & Sex & $\begin{array}{l}\text { Tumor } \\
\text { location }\end{array}$ & $\begin{array}{l}\text { Period from } \\
\text { RFA to DH } \\
\text { onset, months }\end{array}$ & Treatment & Prognosis & $\begin{array}{l}\text { Refer- } \\
\text { ence }\end{array}$ \\
\hline 61 & $\mathrm{~F}$ & S6 and S8 & 13 & surgical repair & dead (HCC rupture) & [11] \\
\hline 72 & M & $\mathrm{S} 4 / 8$ & 18 & surgical repair & alive & {$[12]$} \\
\hline 49 & M & right lobe & 17 & surgical repair & alive & [13] \\
\hline 65 & $\mathrm{~F}$ & S8 & 7 & surgical repair/bowel resection & alive & [14] \\
\hline 46 & $\mathrm{~F}$ & $\mathrm{~S} 2 / 3$ and $\mathrm{S} 5 / 8$ & 19 & laparoscopic surgical repair & alive & [15] \\
\hline 71 & $\mathrm{~F}$ & S7 & 9 & conservative treatment & alive & [16] \\
\hline 61 & M & S5 and S8 & 22 & conservative treatment & alive & [17] \\
\hline 61 & $\mathrm{~F}$ & S8 & 12 & surgical repair/bowel resection & alive & [18] \\
\hline 62 & M & S8 & 96 & laparoscopic surgical repair & alive & [19] \\
\hline 81 & M & S4 and S8 & 18 & surgical repair/bowel resection & alive & [20] \\
\hline 81 & M & S5, S7 and S5/8 & 33 & surgical repair & dead (liver failure) & $\begin{array}{l}\text { present } \\
\text { case }\end{array}$ \\
\hline
\end{tabular}

S = Segment; $\mathrm{DH}=$ diaphragmatic hernia.
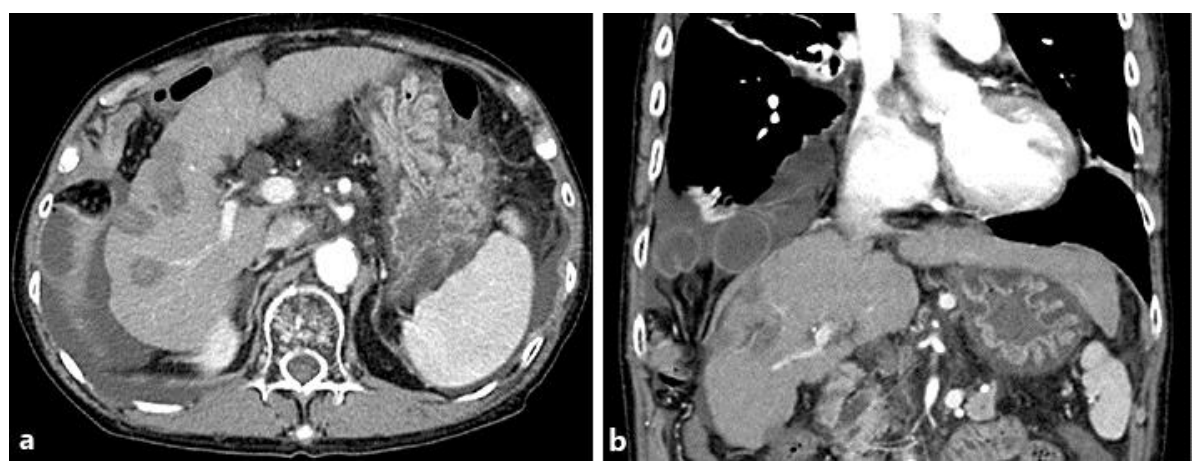

Fig. 1. CT on admission. Diaphragmatic herniation of bowel loops into the right thorax is observed in horizontal (a) and coronal (b) images. 
Saito et al.: Fatal Diaphragmatic Hernia following Radiofrequency Ablation for Hepatocellular Carcinoma: A Case Report and Literature Review
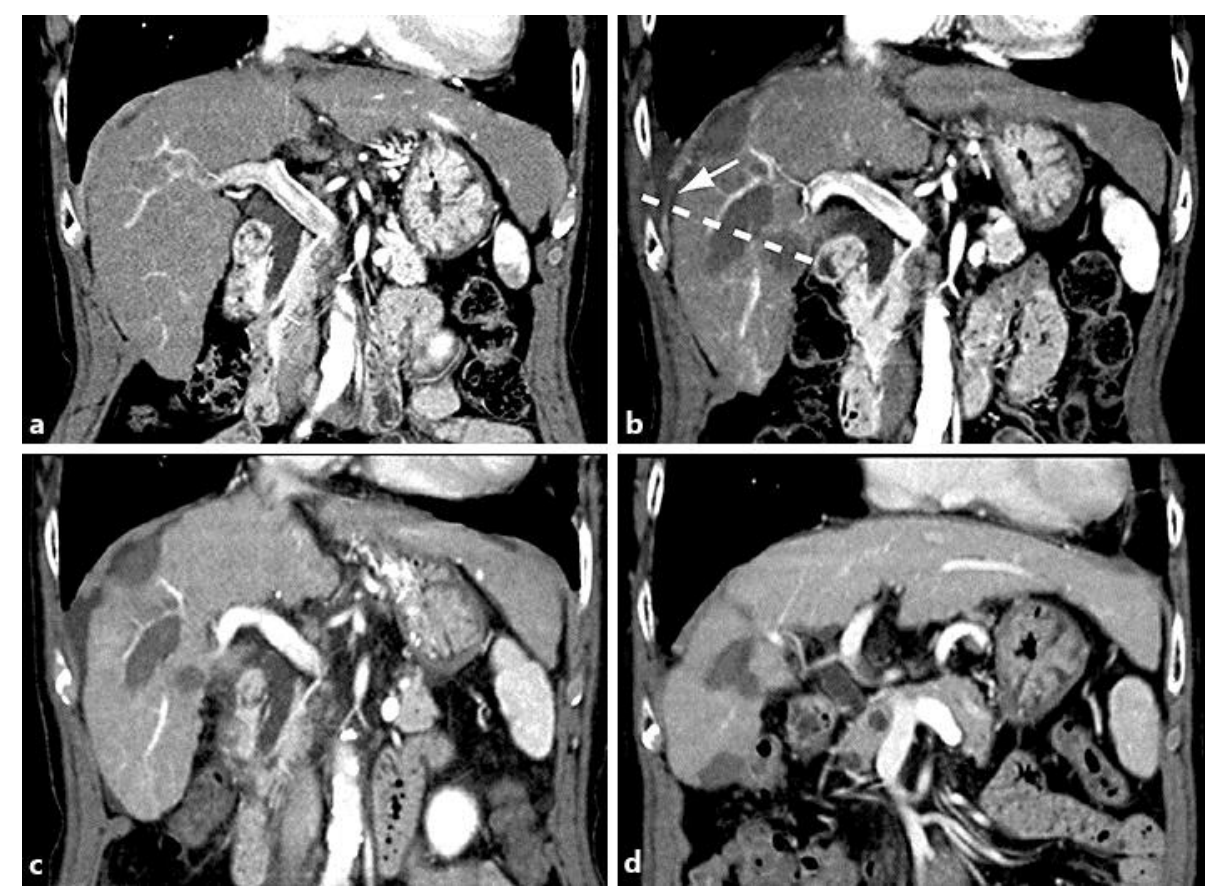

Fig. 2. Findings on coronal CT. Preablation (a) and postablation (b) images of RFA performed 33 months before the onset of diaphragmatic hernia. The dotted line indicates the estimated needle track for RFA. Diaphragmatic thinning along the needle track is shown (arrow). c Diaphragmatic perforation is depicted 24 months before the onset of diaphragmatic hernia. $\mathbf{d}$ Both the progression of the liver atrophy and diaphragmatic perforation are demonstrated 4 months before admission. 